www.jmscr.igmpublication.org

Impact Factor (SJIF): 6.379

Index Copernicus Value: 71.58

ISSN (e)-2347-176x ISSN (p) 2455-0450

crossref DOI: _https://dx.doi.org/10.18535/jmscr/v6i4.84

Journal Of Medical Science And Clinical Research

\title{
Fine Needle Aspiration Cytology versus Fine Needle Non Aspiration Cytology-A Comparative Analysis in Various Breast Lesions
}

\author{
Authors \\ Shalini Srivastava ${ }^{*}$, Alok Kumar Varma ${ }^{2}$ \\ ${ }^{1}$ Assistant Professor, Department of Pathology, Saraswati Medical College, Unnao (U.P.) \\ ${ }^{2}$ Consultant Surgeon, Prem Neurosurgical Clinic, Kanpur Road, Lucknow \\ *Corresponding Author \\ Shalini Srivastava
}

Assistant Professor, Department of Pathology, Saraswati Medical College, Unnao (U.P.), India.

Tel. 9450335521, Email: shalinisri01@ gmail.com

\section{Introduction}

FNAC (Fine Needle Aspiration Cytology) is a well established and reliable diagnostic tool. It is considered an important first line procedure for the assessment of various superficial and deepseated lesions.

FNAC technique was modified by Zajdela et $\mathrm{al}^{1}$ to obtain cytological specimen without aspirationFine needle non aspiration cytology (FNNAC). The technique was based on the principle that capillary action in a fine needle is sufficient to keep the scrapped cells inside the lumen. The technique of non aspiration was especially recommended for obtaining cytological specimens in vascular lesions like thyroid. The non aspiration technique has however been of limited use in breast lesions.

The present study was undertaken to compare the efficacy of FNNAC with that of FNAC in various breast lesions. The techniques were compared objectively to ascertain whether FNNAC could be established as a useful and superior technique in the cytological diagnosis of breast lesions.

\section{Material and Method}

The present study included 140 patients with various breast lesions referred to the Department of Pathology, GSVM Medical College, Kanpur (U.P.), India. After a detailed clinical history and examination, the lesions were sampled by both the techniques, using a 21 gauge needle. A $20 \mathrm{ml}$ syringe was used to create negative pressure for the aspiration technique. All sampling was done by a single operator. The smears were examined without prior knowledge of the technique used, and interpreted based on point scoring system developed by Mair et $\mathrm{al}^{2}$. The two sampling techniques were given scores on 5 parameters:

1. Background blood or clot.

2. Amount of cellular material.

3. Degree of cellular degeneration.

4. Degree of cellular trauma.

5. Retention of appropriate architecture. 
Each parameter was given a score of 0,1 and 2 accordingly.

\begin{tabular}{|c|c|c|}
\hline CRITERION & QUANTITATIVE DESCRIPTION & SCORE \\
\hline \multirow{3}{*}{$\begin{array}{l}\text { Background blood or } \\
\text { clot }\end{array}$} & Large amount; great compromise to diagnosis & 0 \\
\hline & Moderate amount; diagnosis possible & 1 \\
\hline & Minimal; diagnosis easy; specimen of text book quality & 2 \\
\hline \multirow{3}{*}{$\begin{array}{l}\text { Amount of cellular } \\
\text { material }\end{array}$} & Minimal or absent; diagnosis not possible & 0 \\
\hline & Sufficient for cytodiagnosis & 1 \\
\hline & Abundant; diagnosis simple & 2 \\
\hline \multirow{3}{*}{$\begin{array}{l}\text { Degree of cellular } \\
\text { degeneration }\end{array}$} & Marked; diagnosis impossible & 0 \\
\hline & Moderate; diagnosis possible & 1 \\
\hline & Minimal; good preservation; diagnosis easy & 2 \\
\hline \multirow{3}{*}{$\begin{array}{l}\text { Degree of cellular } \\
\text { trauma }\end{array}$} & Marked; diagnosis not possible & 0 \\
\hline & Moderate; diagnosis possible & 1 \\
\hline & Minimal; diagnosis obvious & 2 \\
\hline \multirow{3}{*}{$\begin{array}{l}\text { Retention of } \\
\text { appropriate architecture }\end{array}$} & Minimal to absent; non diagnostic & 0 \\
\hline & $\begin{array}{l}\text { Moderate; some preservation of e.g. follicles, papillae, } \\
\text { acini, flat sheets, syncitia or single cell pattern }\end{array}$ & 1 \\
\hline & $\begin{array}{l}\text { Excellent architectural display closely reflecting } \\
\text { histology, obvious diagnosis }\end{array}$ & 2 \\
\hline
\end{tabular}

The total score for each case by both techniques was calculated and the smears were divided into 3 categories based on the total score.

1. Unsuitable for cytological diagnosis (score 02)

2. Diagnostically adequate (score $3-6$ )

3. Diagnostically superior (score 7-10)

The average score for each parameter by the two techniques was also calculated. All the values were interpreted statistically using student ' $t$ ' test. Statistical significance was considered at a level of $\mathrm{P}=0.5$.

\section{Observation}

140 breast lesions were sampled by both the techniques. The lesions included 28 inflammatory, 89 benign proliferative lesions and 21 malignant while 2 were inconclusive by both the techniques.

Table 1: Performance of FNAC and FNNAC in Total Cases

\begin{tabular}{|l|c|c|}
\hline Result/Performance & FNAC & FNNAC \\
\hline Diagnostically superior & $76(54.3 \%)$ & $87(62.1 \%)$ \\
\hline Diagnostically adequate & $55(39.3 \%)$ & $39(27.9 \%)$ \\
\hline $\begin{array}{l}\text { Unsuitable for } \\
\text { cytological diagnosis }\end{array}$ & $09(6.4 \%)$ & $14(10.0 \%)$ \\
\hline
\end{tabular}

These observations show that FNNAC is more likely to produce diagnostically superior quality material; however it also produces a greater number of unsuitable smears. FNAC was diagnostic in $93.6 \%$ cases, while FNNAC was diagnostic in $90 \%$ cases.
Table 2: Performance of FNAC and FNNAC in Inflammatory Lesions

\begin{tabular}{|l|c|c|}
\hline Result/Performance & FNAC & FNNAC \\
\hline Diagnostically superior & 15 & 15 \\
\hline Diagnostically adequate & 12 & 11 \\
\hline $\begin{array}{l}\text { Unsuitable for } \\
\text { cytological diagnosis }\end{array}$ & 01 & 02 \\
\hline
\end{tabular}

Both FNAC and FNNAC give comparable results in inflammatory lesions

Table 3: Performance of FNAC and FNNAC in Benign Proliferative Lesions

\begin{tabular}{|l|c|c|}
\hline Result/Performance & FNAC & FNNAC \\
\hline Diagnostically superior & 49 & 55 \\
\hline Diagnostically adequate & 35 & 24 \\
\hline $\begin{array}{l}\text { Unsuitable for } \\
\text { cytological diagnosis }\end{array}$ & 05 & 10 \\
\hline
\end{tabular}

FNNAC is more likely to produce diagnostically superior quality material; however it also produces an increased number of inadequate smears. FNAC was diagnostic in $94.4 \%$ cases, while FNNAC was diagnostic in $88.8 \%$ cases.

Table 4: Performance of FNAC and FNNAC in Malignant Lesions

\begin{tabular}{|l|c|c|}
\hline Result/Performance & FNAC & FNNAC \\
\hline Diagnostically superior & 12 & 17 \\
\hline Diagnostically adequate & 08 & 04 \\
\hline $\begin{array}{l}\text { Unsuitable for } \\
\text { cytological diagnosis }\end{array}$ & 01 & 00 \\
\hline
\end{tabular}

FNNAC is more likely to produce diagnostically superior quality material. No unsuitable smears 
were seen by FNNAC compared to one by FNAC. The unsuitable smear was due to large amount of blood and low cellularity.

Table 5: Average Score for Each Parameter (Total Cases)

\begin{tabular}{|c|l|c|c|}
\hline S.N. & \multicolumn{1}{|c|}{ CRITERION } & FNAC & FNNAC \\
\hline 1 & Background blood or clot & 1.157 & 1.292 \\
\hline 2 & Amount of cellular material & 1.307 & 1.300 \\
\hline 3 & Degree of cellular trauma & 1.292 & 1.328 \\
\hline 4 & Degree of cellular trauma & 1.171 & 1.192 \\
\hline 5 & $\begin{array}{l}\text { Retention of appropriate } \\
\text { architecture }\end{array}$ & 1.149 & 1.164 \\
\hline
\end{tabular}

These observations show that the average score was better by FNNAC compared to FNAC for all parameters except amount of cellular material which was slightly higher for FNAC. In individual groups similar results were obtained except the cellular yield was better in malignant lesions. The difference between the scores of the parameter 'Background blood or clot' by the two techniques was found to be statistically significant at $\mathrm{p}=$ 0.05 . The difference between the scores of the remaining four parameters by the two techniques showed no statistical significance.

Table 6: Average of Total Score in Each Category

\begin{tabular}{|l|c|c|}
\hline & FNAC & FNNAC \\
\hline TOTAL CASES & 6.15 & 6.35 \\
\hline INFLAMMATORY & 6.21 & 6.50 \\
\hline BENIGN PROLIFERATIVE & 6.22 & 6.34 \\
\hline MALIGNANT & 6.285 & 6.76 \\
\hline
\end{tabular}

Average score per case on a total score of 10 was also better by FNNAC. Similar results were seen in individual groups also.

\section{Discussion}

The aim of the present study was to compare the conventional Fine needle aspiration technique with the Fine needle non aspiration technique in various breast lesions. In the present study it was observed that FNNAC gave greater number of diagnostically superior smears as compared to FNAC, however diagnostically adequate smears were more frequently obtained by FNAC as compared to FNNAC. The number of unsatisfactory smears was also more by FNNAC.
These observations were in agreement with several prior studies.

Mair et $\mathrm{al}^{2}$ and Savage et $\mathrm{al}^{3}$ also noted that FNNAC gave superior quality smears, although conventional FNAC was diagnostic in greater number of cases, but this difference was not statistically significant. The study by Ghosh et $\mathrm{al}^{4}$ also showed similar results. The difference in their study was found to be statistically significant. Baksh et $\mathrm{al}^{5}$ in their study of 145 breast lesions obtained more diagnostically superior smears by FNNAC, and more diagnostically adequate smears by FNAC. This difference was statistically significant. These findings were similar to the findings of the present study; however the difference in our study was not statistically significant.

The study by Zajdela et $\mathrm{al}^{1}$ on mammary lesions gave insufficient cellular yield with fine needle alone in $5.5 \%$ of the lesion. The same incidence (6\%) was recorded with aspiration techniques. The present study gave smears unsatisfactory for cytological diagnosis in $6.4 \%$ of cases by aspiration technique and $10 \%$ by non aspiration technique. They also noted that the trauma to the cells is reduced by non aspiration technique, which was similar to the findings of our study.

In the present study the lesions were categorized into inflammatory lesion, benign proliferative lesions and malignant lesions. The inflammatory lesions showed almost similar results by both the techniques. In the benign proliferative lesions FNNAC gave greater number of diagnostically superior smears (FNAC-49, FNNAC-55), diagnostically adequate smears were more by FNAC (FNAC-35, FNNAC-24) and diagnostically unsatisfactory smears were more by FNNAC (FNAC-05, FNNAC-10). In the malignant lesions again, FNNAC gave greater number of diagnostically superior smears (FNAC12, FNNAC-17). Greater number of diagnostically adequate smears was obtained by FNAC than by FNNAC (FNAC-8, FNNAC-4). There was one unsatisfactory smear by FNAC (This was due to 
large amount of blood and low cellularity) compared to none by FNNAC.

In the study by Raghuveer et $\mathrm{al}^{6}$, of the 27 breast cases FNS (FNNAC) yielded diagnostic material in $70.38 \%$ cases while FNA was diagnostic in $85.19 \%$, thus establishing definite superiority. However FNS seemed to be better for diagnosing malignant lesions while FNA appeared better for diagnosing benign ones. The present study also shows better results with FNAC for benign lesions while the non aspiration technique gave better results for malignant lesions

Ciatto $\mathrm{S}$ et $\mathrm{al}^{7}$ found that the inadequacy rate was the same in 166 cancers (6.6\%), whereas a significant difference was recorded in favour of aspiration (13.6 versus 24.4\%) in 368 benign masses. When inadequate results were excluded, the accuracy of the two modalities was almost the same. The present study also shows greater number of inadequate smears by FNNAC in benign lesions.

Bharathi $\mathrm{K}$ et $\mathrm{al}^{8}$ also noted that the diagnostic adequacy was more by FNAC, but this difference was not statistically significant. They also noted that FNAC was the best choice for fibrous and cystic lesions, while in malignant lesions both the techniques were comparable and yielded adequate material. These findings were similar to our study. However according to their study FNAC technique also gave diagnostically superior quality smears, while in our study FNNAC gave more superior quality smears.

On comparing the average score for each parameter, higher average scores were seen with FNNAC for all parameters except for amount of cellular material which was higher for FNAC. The difference between the scores for the parameter background blood was found to be statistically significant. None of the differences for other scores were found to show statistical significance. In individual groups, the average score for the parameter- amount of cellular material was higher in malignant lesions.

In the studies conducted by Mair et $\mathrm{al}^{2}$, there was no statistically significant difference between the efficacies of the two sampling techniques for any of the parameters studied. Baksh et $\mathrm{al}^{5}$ in their study on breast lesions, also found the differences between all the individual parameters as observed in FNAC and FNNAC smears to be insignificant. Ghosh et $\mathrm{al}^{4}$ found statistically significant better results by FNA for the parameter amount of cellular material for breast lesions only. This difference in scores was not significant in our study.

Kamal et $\mathrm{al}^{9}$ in their study on thyroid lesions, concluded that smears prepared by FNC (FNNAC) displayed cellular material which was more concentrated, less damaged and less likely to be obscured by blood. A statistically significant difference in favour of FNC was observed for the parameter amount of cellular material.

Kumarsinghe et $\mathrm{al}^{10}$ in their study found that though discomfort felt and contamination with blood was less by non aspiration technique, the overall cellular yield was unsatisfactory for breast lesions. The cellular yield was, however comparable for malignant breast lesions by both the techniques. Our study gave comparable cellular yield by both the techniques, with slightly better cellular yield by FNAC. Higher inadequate smears were seen by FNNAC in some benign lesions.

The average score (on adding scores of all parameters) for each case by FNAC and FNNAC were also calculated. Better average score for the total series was: FNAC-6.15, FNNAC-6.35. In individual groups also FNNAC gave better scores.

\section{Conclusion}

All the above observations lead to the conclusion that FNNAC is a qualitatively superior technique. Quantitatively, also it is at par with FNAC except in cases of benign lesions, where it gives greater number of inadequate smears. This is usually seen in cases with low cellularity and cystic lesions. FNNAC is especially useful in sampling of malignant lesions. On a subjective level, FNNAC allows greater ease of lesion sampling. There is a better control of hand during the procedure and so 


\section{JMSCR Vol||06||Issue||04||Page 505-509||April}

the method is extremely useful in sampling small lesions. The operator also gets a better perception of the consistency of the lesion. On the whole FNNAC is a good alternative to FNAC. Using either of the two techniques, depending on the lesion, or double sampling using both techniques will give superior quality smears with decreased number of inadequate samples.

\section{References}

1. Zajdela A, Zillhardt $\mathrm{P}$, Voillemot $\mathrm{N}$ : Cytological diagnosis by fine needle sampling without aspiration. Cancer 1987;59: 1201-1205.

2. Mair S, Dunbar F, Becker P J, DuPlesis $\mathrm{W}$ : Fine needle cytology- Is aspiration suction necessary? A study of 100 masses in various sites. Acta cytol 1989;33 (6):809-813.

3. Savage C A, Hopper K D, Abendroth C S, Hartzel J S, TenHave T R: Fine needle aspiration biopsy versus fine needle capillary (non aspiration) biopsy: in vivo comparison. Radiology 1995; 195(3):815819.

4. Ghosh A, Misra R K, Sharma S P, Singh H $\mathrm{N}$ : Aspiration vs non aspiration technique of cytodiagnosis- A critical evaluation in 160 cases. Indian J Pathol Microbiol 2000; 43:107-112.

5. Baksh S, Masih K, Singh S, Das S: Diagnostic utility of fine needle nonaspiration cytology versus fine needle aspiration cytology in breast masses. Indian J Pathol Microbiol. 2004; 47:319321.

6. Raghuveer $\mathrm{CV}^{1}$, Leekha I, Pai MR, Adhikari P: Fine Needle Aspiration cytology versus Fine Needle Sampling without aspiration. A prospective study of 200 cases. Indian J Med Sci 2002; 56:431439.

7. Ciatto S, Catania S, Bravetti P, Bonardi R, Cariaggi P, Pacifico E. Fine-needle cytology of the breast: a controlled study of aspiration versus non aspiration. Diagn Cytopathol 1991; 7(2):125-127.

8. Bharathi K, Venktesh S. Comparision of aspiration Vs non aspiration techniques in fine needle cytology of breast lesions. Journal of Medical Science and Tecnology 2012;1(2):6-16.

9. Kamal M M, Argune D G, Kulkarni H R: Comparative study of fine needle aspiration and fine needle capillary sampling of thyroid lesions. Acta Cytol 2002; 46(1):30-34.

10. Kumarasinghe MP, Sheriffdeen AH. Fine needle sampling without aspiration. Pathology 1995;27(4):330-2. 